Check for updates

Cite this: RSC Adv., 2019, 9, 22883

\title{
Heavy metal removal from aqueous systems using hydroxyapatite nanocrystals derived from clam shells
}

Received 3rd June 2019 Accepted 18th July 2019

DOI: $10.1039 / c 9 r a 04198 b$

rsc.li/rsc-advances

\author{
Dariela Núñez, (D) *a Jon Ander Serrano, ${ }^{\text {* }}$ Aritz Mancisidor, ${ }^{a}$ Elizabeth Elgueta, ${ }^{a}$ \\ Kokkarachedu Varaprasad, (D) a Patricio Oyarzún, ${ }^{\text {b }}$ Rodrigo Cáceres, ${ }^{a}$ Walther Ide ${ }^{a}$ \\ and Bernabé L. Rivas ${ }^{c}$
}

Hydroxyapatite (HA) was synthesized by wet chemical precipitation, using clam shell (CS) waste as feedstock. SEM and TEM observation of the produced hydroxyapatite revealed the presence of rod-shaped nanocrystals, while XRD and EDS analyses confirmed the characteristic patterns of hydroxyapatite molecules. This material was subsequently employed as a sorbent for heavy metal removal from aqueous solutions, both in batch and column equilibrium procedures. In batch studies, higher sorption efficiencies were obtained at pH 5, with the highest adsorption capacities of 265,64 , and $55 \mathrm{mg} \mathrm{g}^{-1}$ for $\mathrm{Pb}(॥), \mathrm{Cd}(॥)$, and $\mathrm{Cu}(॥)$, respectively. In addition, an adsorption capacity of $42.5 \mathrm{mg} \mathrm{g}^{-1}$ was determined using a CS-HA packed bed column fed with a solution of $\mathrm{Pb}(I)$. Finally, the breakthrough curve was fitted with Thomas model in order to predict column behavior and scaling up.

\section{Introduction}

Safe and clean drinking water is essential for human life. However, its availability is becoming scarce as a consequence of the contamination of clean resources and the effects of global warming. ${ }^{1,2}$ Water pollution due to the presence of heavy metals represents a serious threat to living organisms and to the environment, since they are toxic, non-degradable, and they tend to bio-accumulate. Lead can severely impact the central nervous, renal, reproductive, hematopoietic and hepatic systems. ${ }^{3}$ Cooper is toxic at high concentrations, since it could produce cellular and tissue damage leading to Wilson disease in humans. ${ }^{4}$ Cadmium is an established human carcinogen, which has been associated with the development of prostate, kidney, liver, hematopoietic system and stomach cancer. ${ }^{4}$ Anthropogenic activities, such as mining and other industrial processes may introduce these contaminants into the water. ${ }^{5}$ Likewise, natural dissolution of heavy metals is also an important source of contamination, because they are widely distributed in the Earth's surface. ${ }^{6}$ Thus, the removal of metal ions is paramount to contribute to maintain these contaminants under safe concentrations. Traditional purification technologies include reverse osmosis, ion-exchange, precipitation, membrane technology, and adsorption. ${ }^{7-10}$ However,

${ }^{a}$ Centro de Investigación de Polimeros Avanzados, CIPA, Avenida Collao 1202, Edificio de Laboratorios, Concepción, Chile.E-mail: d.nunez@cipachile.cl; Tel: +56 413111859 ${ }^{b}$ Facultad de Ingeniería y Tecnología, Universidad San Sebastián, Lientur 1457, Concepción 4080871, Chile

'Polymer Department, Faculty of Chemistry, University of Concepción, Casilla 160-C, Concepción, Chile adsorption-based technologies have emerged as simple, efficient and economic alternatives. ${ }^{5}$

The use of mollusk shells to produce low cost sorbents is an attractive approach, especially given its high content of calcium carbonate that makes these waste materials excellent feedstock candidates to produce hydroxyapatite $\left(\mathrm{HA} ; \mathrm{Ca}_{10}\left(\mathrm{PO}_{4}\right)_{6}(-\right.$ $\left.\mathrm{OH})_{2}\right)^{11,12}$ We previously showed that clam shells have higher calcium carbonate content compared with mussel shells and eggshells, ${ }^{11}$ enabling thus a higher conversion rate into HA. In addition, because synthetic HA is produced through stoichiometric conversion from calcium carbonate, the resulting product is highly pure, with no residual content of reactants or by products. ${ }^{11}$ By contrast, HA extracted from bones or other natural sources is non-stoichiometric, since it contains trace elements such as $\mathrm{Na}^{+}, \mathrm{Zn}^{2+}, \mathrm{Mg}^{2+}, \mathrm{K}^{+}, \mathrm{Si}^{2+}, \mathrm{Ba}^{2+}, \mathrm{F}^{-}$, and $\mathrm{CO}_{3}{ }^{2-} \cdot{ }^{12-14} \mathrm{Up}$ to date, synthetic and natural HAs have been reported for different applications including biosorption for removing of heavy metals. ${ }^{15,16}$ Heavy metal sorption studies have been performed using commercial $\mathrm{HA}^{17-22}$ or HA produced from chemical reagents ${ }^{23-26}$ while some studies account for the employment of bio-wastes for HA synthesis and sorption applications, using as raw material Persian Gulf corals, ${ }^{27}$ eggshell, ${ }^{28-31}$ bone char, ${ }^{32}$ mammalian bone meal, ${ }^{25}$ fish scales ${ }^{33}$ and microbial precipitated calcite. ${ }^{34}$ However, only a few studies focus on batch and column equilibrium procedures for heavy metal sorption studies using HA synthetized from biogenic sources. In addition, regeneration studies with synthetic HA, either pure or composites, have shown only slight loss of adsorption efficiency after consecutive adsorption-desorption cycles, proving the material can be reused for long term applications in water treatment. ${ }^{35,36}$ 
In the present study, HA was synthesized from clam shells as starting material (CS-HA) using wet chemical precipitation. Material characterization was performed through X-ray diffraction (XRD), transmission electron microscopy (TEM), and scanning electron microscopy (SEM) coupled with energydispersive X-ray spectroscopy (EDX). The effect of $\mathrm{pH}$, contact time (kinetic studies), maximum sorption capacity, and selectivity were tested on CS-HA using $\mathrm{Pb}(\mathrm{II}), \mathrm{Cd}(\mathrm{II})$, and $\mathrm{Cu}(\mathrm{II})$ solutions in batch procedure. A column equilibrium procedure was also included using a CS-HA packed bed system. The results were fitted using Thomas Model.

\section{Experimental}

\subsection{Production of calcium oxide from clam shells}

Clam shells were collected from local markets in the province of Concepción, Chile. The shells were grinded with a laboratory mill (A11 basic Analytical mill, IKA) and sieved using a 100 Mesh stainless steel screen. The fine sieved fraction of the powdered shells was calcined in a furnace (Thermolyne F6010, Thermoscientific), firstly at $550^{\circ} \mathrm{C}$ for $1 \mathrm{~h}$ and then at $900{ }^{\circ} \mathrm{C}$ for $3 \mathrm{~h}$, to remove organic material in the shell and to convert the calcium carbonate content into calcium oxide $(\mathrm{CaO})$. Finally, the calcined powder was triturated in a ceramic mortar.

\subsection{Synthesis of nano-hydroxyapatite}

CS-HA was prepared by wet chemical precipitation using $100 \mathrm{~mL}$ of $0.6 \mathrm{M}$ phosphoric acid $\left(\mathrm{H}_{3} \mathrm{PO}_{4} 85 \%\right.$ p.a. $)$ and $100 \mathrm{~mL}$ of $1 \mathrm{M}$ calcium hydroxide $(5.6 \mathrm{~g}$ of $\mathrm{CaO}$ were dissolved in $100 \mathrm{~mL}$ of water). The solution of $\mathrm{H}_{3} \mathrm{PO}_{4}$ was added to the $\mathrm{Ca}(\mathrm{OH})_{2}$ solution dropwise at a flow rate of 2.5 $\mathrm{mL} \min ^{-1}$ using a syringe pump. The reaction vessel was stirred at $1500 \mathrm{rpm}$, maintained at $40{ }^{\circ} \mathrm{C}$ and the $\mathrm{pH}$ was adjusted to 10 using $1 \mathrm{M} \mathrm{NaOH}$. The final suspension was stirred overnight at room temperature. The obtained precipitate was washed three times with distilled water by consecutive centrifugation $(10000 \mathrm{rpm})$. Finally, the resulting precipitate was dried at $40{ }^{\circ} \mathrm{C}$ for three days.

\subsection{Characterization of hydroxyapatite powder}

The phase composition of CS-HA was determined by X-ray diffractometry (XRD-Bruker, D4 Endeavor) at $40 \mathrm{kV}$ and 20 $\mathrm{mA}$, using $\mathrm{Cu} \mathrm{K} \alpha$ radiation $(\lambda=1.5406 \AA)$. Diffractograms were recorded in a $2 \theta$ range $5-70^{\circ}$ (step size $0.02^{\circ}$, step time $141 \mathrm{~s}$ ). The morphology of CS-HA nanocrystals were examined by scanning electron microscopy (SEM) (ETEC Autoscan) equipped with energy-dispersive X-ray spectroscopy (EDX), and transmission electron microscopy (TEM) (JEOL/JEM 1200 EX II).

\subsection{Metal solution preparation and analysis}

The solutions were prepared using $\mathrm{Cu}\left(\mathrm{NO}_{3}\right)_{2}, \mathrm{Cd}\left(\mathrm{NO}_{3}\right)_{2}$, and $\mathrm{Pb}\left(\mathrm{NO}_{3}\right)_{2}$ standard solutions (Merck Co., Germany). Atomic absorption spectroscopy (AAS) (PinAAcle 900F, PerkinElmer) was used for cation concentration analysis. The flame atomizer was supplied with $2.5 \mathrm{~L} \mathrm{~min}^{-1}$ of acetylene and $10 \mathrm{~L} \mathrm{~min}^{-1}$ of air. An electrode discharge lamp (EDL) was used as the radiation source for lead and cadmium, and a cathodic lamp for copper. Detection wavelengths were $324.7 \mathrm{~nm}$ for copper, $228.8 \mathrm{~nm}$ for cadmium, and $283.3 \mathrm{~nm}$ for lead.

\subsection{Influence of $\mathrm{pH}$ on adsorption}

The sorption of $\mathrm{Cu}$ (II), $\mathrm{Cd}$ (II), and $\mathrm{Pb}$ (II) was assessed at $\mathrm{pHs} 3,4$, and 5 . Batch experiments were carried out with $40 \mathrm{mg}$ of CS-HA in $10 \mathrm{~mL}$ of metal solution $\left(200 \mathrm{mg} \mathrm{L}^{-1}\right)$ for $24 \mathrm{~h}$ at $25^{\circ} \mathrm{C}$ and $140 \mathrm{rpm}$. At the end of the contact time, the sample was centrifuged and metal concentration in the supernatant was measured by AAS. The experiments were carried out in triplicate.

\subsection{Influence of contact time on adsorption}

The effect of the contact time between the sorbent material and the heavy metal solution was assessed at 10, 20, 40, 60, $80,120,180,360$, and $1440 \mathrm{~min}$ at $25{ }^{\circ} \mathrm{C}$. For each metal $(\mathrm{Cu}$ (II), $\mathrm{Cd}(\mathrm{II})$, and $\mathrm{Pb}(\mathrm{II}))$, a set of 9 solution flasks were prepared using $40 \mathrm{mg}$ of CS-HA with $10 \mathrm{~mL}$ of the corresponding heavy metal ion solution $\left(200 \mathrm{mg} \mathrm{L}^{-1}\right)$. The mixtures were subsequently centrifuged and the supernatants were analyzed for heavy metal content by AAS. The experiments were carried out in triplicate.

\subsection{Selectivity study}

$10 \mathrm{~mL}$ of a multicomponent solution containing $\mathrm{Cu}$ (II), $\mathrm{Cd}(\mathrm{II})$, and $\mathrm{Pb}(\mathrm{II})$ at concentration of $200 \mathrm{mg} \mathrm{L}^{-1}$ each metal ion were contacted with $40 \mathrm{mg}$ of CS-HA. After $1 \mathrm{~h}$ of contact time the solutions were centrifuged and analyzed by AAS for heavy metal content. The experiments were carried out in triplicate.

\subsection{Sorption capacity studies}

Sorption capacities for $\mathrm{Pb}(\mathrm{II}), \mathrm{Cd}(\mathrm{II})$, and $\mathrm{Cu}(\mathrm{II})$ were determined at pH 5 and $25{ }^{\circ} \mathrm{C}$ using solutions prepared at the following concentrations: $100,200,300,400$, and $500 \mathrm{mg} \mathrm{L}^{-1}$, for $\mathrm{Cd}(\mathrm{II})$ and $\mathrm{Cu}$ (II), and 100, 200, 300, 400, 500, 750, 1000, and $2000 \mathrm{mg} \mathrm{L}^{-1}$ for $\mathrm{Pb}(\mathrm{II}) .40 \mathrm{mg}$ of CS-HA were contacted with $10 \mathrm{~mL}$ of each solution. The sorption capacity at the equilibrium $\left(q_{\mathrm{e}}\right)$ was calculated using eqn (1).

$$
q_{\mathrm{e}}=\frac{\left(C_{0-} C_{\mathrm{e}}\right) V}{X}
$$

where $q_{\mathrm{e}}$ is the amount of adsorbed metal per weight of adsorbent material at the equilibrium, expressed in $\mathrm{mg} \mathrm{g}^{-1} . C_{0}$ and $C_{\mathrm{e}}$ correspond to the initial concentration and the concentration at the equilibrium $\left(\mathrm{mg} \mathrm{L}^{-1}\right)$, respectively. The volume of the solution is represented by $V(\mathrm{~L})$ and the dry weight of the sorbent material is denoted by $X(\mathrm{~g})$.

\subsection{Column study}

The removal of $\mathrm{Pb}$ (II) was studied at laboratory-scale using a glass column ( $1 \mathrm{~cm} \Phi \times 0.4 \mathrm{~cm}$ height $)$ filled with $0.2 \mathrm{~g}$ of CS-HA, according to the experimental setup presented in 


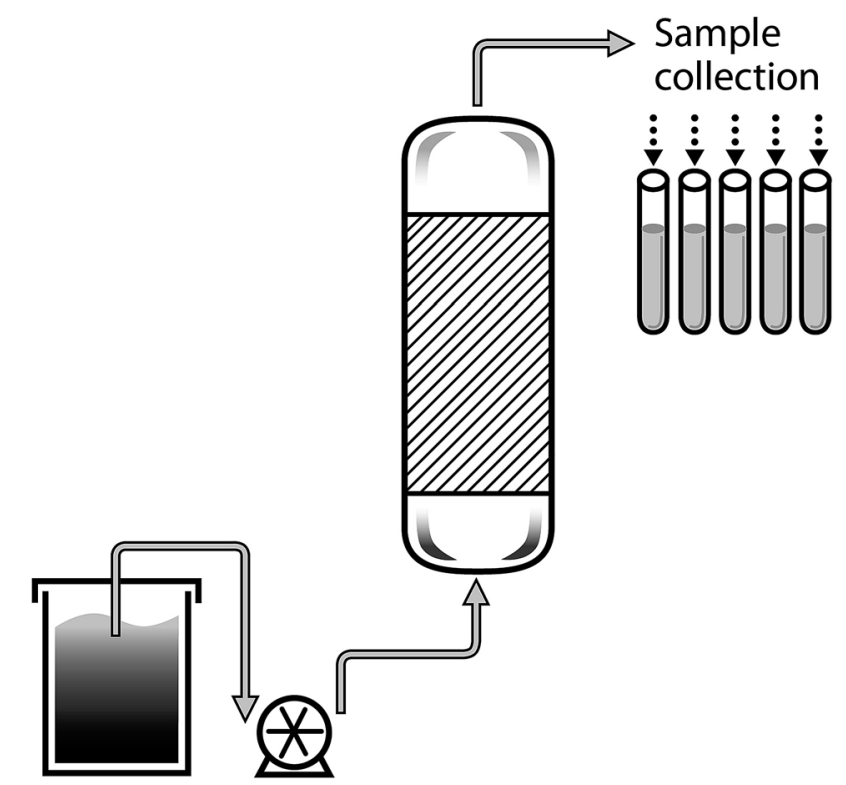

Fig. 1 Diagram of the packed bed column system.

Fig. 1. The system was operated in up flow mode, by feeding a synthetic solution of $\mathrm{Pb}(\mathrm{II})$ prepared at $30 \mathrm{mg} \mathrm{L}^{-1}$ and $\mathrm{pH} 5$ at a constant flow rate of $1.2 \mathrm{~mL} \min ^{-1}$ using peristaltic pump (120 S, Watson Marlow).

Samples were manually collected every 20 minutes from the outflow. The $\mathrm{Pb}$ (II) concentration in the samples was measured by AAS.

\section{Results and discussion}

\subsection{Characterization of the materials}

The crystalline structure of synthesized CS-HA was determined from the XRD patterns (see Fig. 2a), confirming the presence of reflections peaks $(25.77,31.87,33.01,34.14,39.98,46.80,49.55$, and $53.12^{\circ}$ ) corresponding to its main diffraction planes: (002), (300), (202), (310), (222), (213), and (004). ${ }^{37}$ The crystalline peaks were identified using the WinXPow software (JCPDS Card No 90432). In addition, the size and morphology of synthesized CSHA was analyzed by electronic microscopy (TEM/SEM), showing the presence of rounded and smooth-surface aggregates composed of rod-like nanocrystals of approximately $80 \mathrm{~nm}$ and $20 \mathrm{~nm}$ diameter (see Fig. $2 \mathrm{~b}$ and d). Finally, the elemental composition of CS-HA determined from the EDS spectra confirmed the presence of $\mathrm{Ca}, \mathrm{O}$, and $\mathrm{P}$, in agreement with the result of XRD (see Fig. 2c).

\subsection{Influence of $\mathrm{pH}$ on adsorption}

Fig. 3 shows the sorption efficiencies of CS-HA for $\mathrm{Cu}(\mathrm{II}), \mathrm{Cd}(\mathrm{II})$, and $\mathrm{Pb}(\mathrm{II})$ at $\mathrm{pH} 3,4$, and 5 and initial concentration of $200 \mathrm{mg} \mathrm{L}^{-1}$. Higher sorption efficiencies were obtained at $\mathrm{pH} 5$ for $\mathrm{Cu}(\mathrm{II}), \mathrm{Cd}(\mathrm{II})$, while for $\mathrm{Pb}$ (II) the sorption efficiency remained over $99 \%$ for the three $\mathrm{pH}$ conditions tested. At pH 5 the sorption efficiencies were $96.8 \pm 0.3$ and $96.1 \pm 0.6 \%$ for $\mathrm{Cd}(\mathrm{II})$ and $\mathrm{Cu}(\mathrm{II})$, respectively. However, at $\mathrm{pH} 4$ the sorption efficiencies for these metals slightly dropped to $94.5 \pm 0.7$ and $95.6 \pm 0.6 \%$, respectively. At pH 3, the sorption efficiencies also fell to $93.1 \pm$
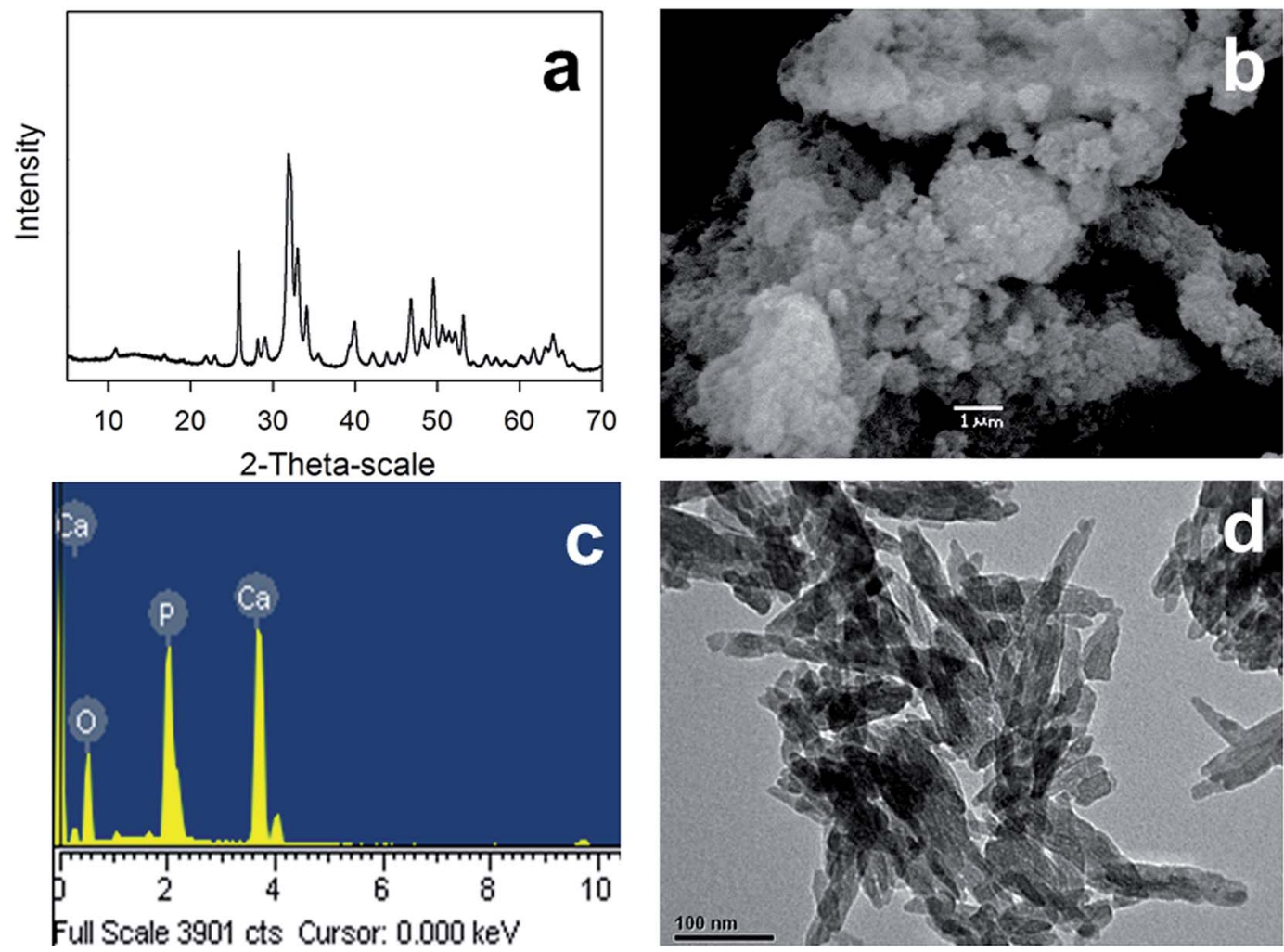

Fig. 2 Hydroxyapatite nanoparticles characterization using (a) XRD, (b) SEM, (c) EDX, and (d) TEM. 

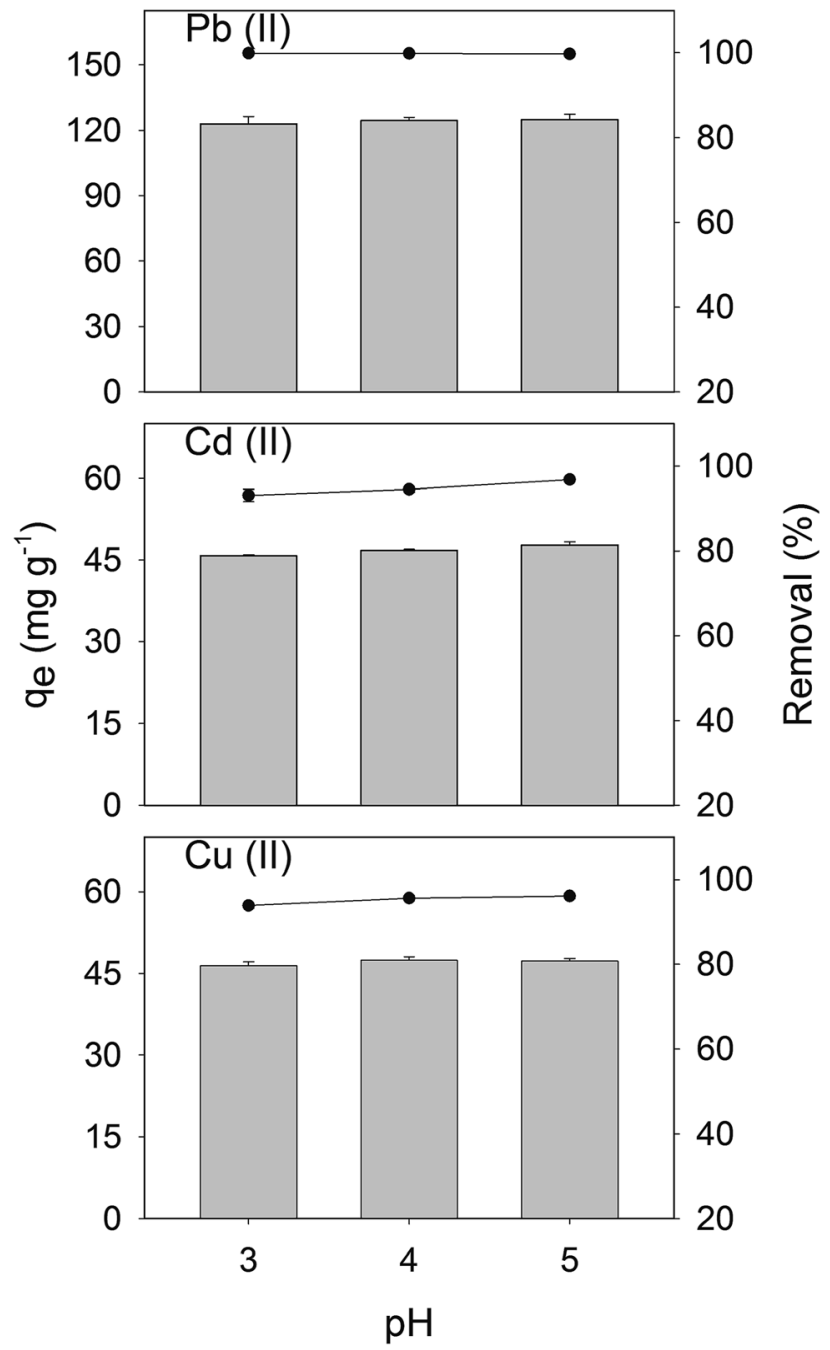

Fig. 3 Sorption studies of $\mathrm{CS}-\mathrm{HA}$ for $\mathrm{Cu}(॥), \mathrm{Cd}(॥)$, and $\mathrm{Pb}(॥)$ at $\mathrm{pH} 3,4$, and 5 , with an initial metal concentration of $200 \mathrm{mg} \mathrm{L}^{-1}$. Error bars indicate the standard deviation of triplicate.

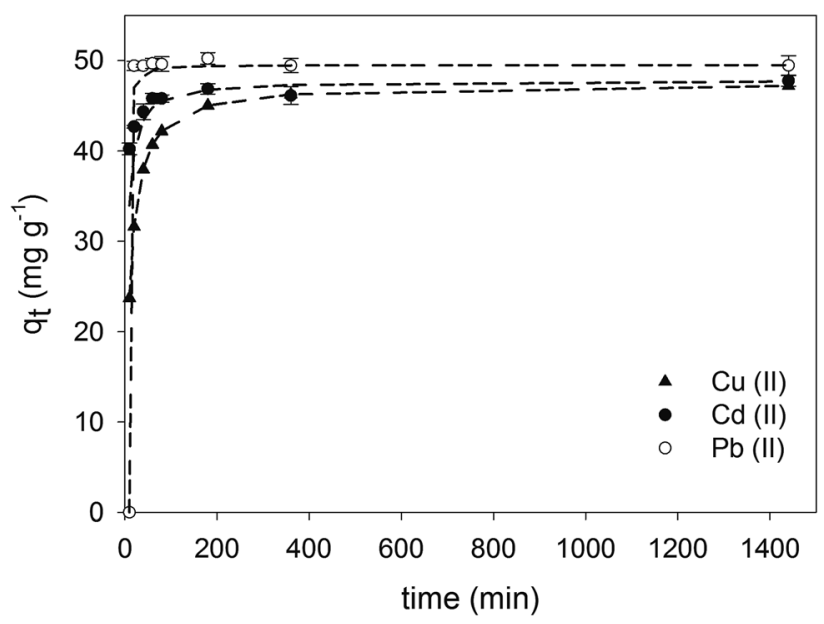

Fig. 4 Sorption capacities of CS-HA using single metal solutions of $\mathrm{Cu}(I), \mathrm{Cd}\left({ }^{\prime}\right)$, and $\mathrm{Pb}(॥)$ for $10,20,40,60,80,180,360 \mathrm{~min}$, and $24 \mathrm{~h}$ of contact time. Error bars correspond to the standard deviation of triplicate. Short dashed line indicates fitting to pseudo second-order kinetics.
1.5 and $93.9 \pm 0.6 \%$, respectively. Therefore, given the detrimental effect on the sorption efficiency observed at $\mathrm{pH} 3$ and 4 , the $\mathrm{pH}$ selected was 5 for the rest of the experiments.

\subsection{Effect of contact time on adsorption}

Sorption curves demonstrate that $\mathrm{Pb}$ (II) reached $99.0 \pm 1.0 \%$ of efficiency at the first $10 \mathrm{~min}$ and complete removal was achieved after 20 min of contact time (see Fig. 4). For $\mathrm{Cu}$ (II) and $\mathrm{Cd}$ (II) the sorption efficiencies were, respectively, $65.8 \pm 0.4$ and $81.3 \pm 0.1 \%$ respectively at the first $10 \mathrm{~min}$ of contact and continued to increase up to $80.9 \pm 0.1$ and $92.0 \pm 0.2 \%$ at $60 \mathrm{~min}$ of contact time. The highest efficiencies were obtained after $24 \mathrm{~h}$, reaching $93 \%$ for $\mathrm{Cu}$ (II) and $\mathrm{Cd}$ (II). The contact time selected for the experiments was $60 \mathrm{~min}$, since the removal capacity obtained at this time was over $90 \%$ of the maximum capacity obtained at $24 \mathrm{~h}$ of contact time.

\subsection{Selectivity study}

The selectivity of metal removal was studied using a multicomponent solution containing $\mathrm{Cu}(\mathrm{II}), \mathrm{Cd}(\mathrm{II})$, and $\mathrm{Pb}(\mathrm{II})$ at a concentration of $200 \mathrm{mg} \mathrm{L}^{-1}$ for each ion (see Fig. 5). The removal efficiency of $\mathrm{Pb}$ (II) was not affected by the presence of the other metal ions, reaching nearly complete removal under this condition. However, a detrimental effect on the sorption capacity was observed for $\mathrm{Cd}(\mathrm{II})$ and $\mathrm{Cu}$ (II) in the presence of other metal ions, which results consistent with other works showing a competitive effect among certain metal ions. ${ }^{21}$ By contrast, the favorable sorption of $\mathrm{Pb}$ (II) can been attributed to its high electronegativity (2.33, Pauling) and ionic radius (1.19 $)$ ), which is in the range of $\mathrm{Ca}\left(\right.$ II) ionic radius $(0.99 \AA){ }^{38}$ this phenomenon has been associated with a high sorption selectivity for HA. ${ }^{22,39}$ The electronegativity of $\mathrm{Cu}(\mathrm{II})$, and $\mathrm{Cd}(\mathrm{II})$ are 1.9 and 1.69 (Pauling), and their ionic radius are $0.73 \AA$ and $0.97 \AA{ }^{38}$ respectively.

\subsection{Sorption capacity studies at different initial concentrations}

$\mathrm{Pb}$ (II) sorption capacities were higher than those of $\mathrm{Cu}$ (II) and $\mathrm{Cd}(\mathrm{II})$ in the concentration range investigated (see Fig. 6). This

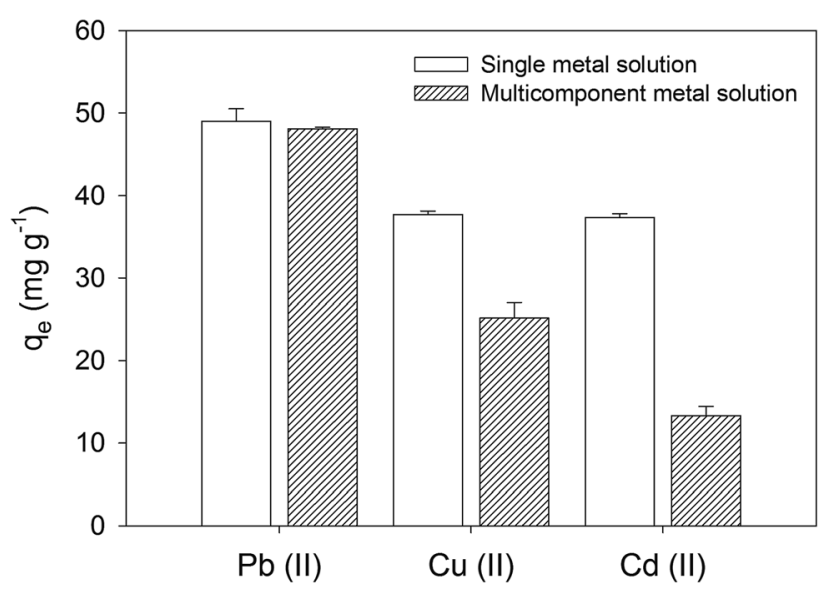

Fig. 5 Sorption efficiencies and capacities obtained with multielement solution containing $\mathrm{Cu}(\Perp), \mathrm{Cd}(\Perp)$, and $\mathrm{Pb}(\Perp)$. Error bars correspond to the standard deviation of triplicate. 



Fig. 6 Sorption capacities of $\mathrm{Pb}(॥), \mathrm{Cu}(॥)$, and $\mathrm{Cd}(॥)$. Error bars correspond to the standard deviation of triplicate. Langmuir and Freundlich isotherms are presented inside main graph for each metal.

result is consistent with previous reports using pure HA synthesized by wet chemical precipitation. ${ }^{22,25}$ The sorption capacities of $\mathrm{Cu}$ (II) and $\mathrm{Cd}(\mathrm{II})$ were similar, which could account for the lower electronegativity of $\mathrm{Cd}(\mathrm{II})$ but higher ionic radius. The highest sorption capacities were 265,64 and $55 \mathrm{mg} \mathrm{g}^{-1}$, for $\mathrm{Pb}(\mathrm{II}), \mathrm{Cd}(\mathrm{II})$, and $\mathrm{Cu}(\mathrm{II})$, respectively.
Table 1 Pseudo-second-order kinetics parameters for the sorption of $\mathrm{Pb}(॥), \mathrm{Cd}(॥)$, and $\mathrm{Cu}(॥)$

\begin{tabular}{lllll}
\hline & $\begin{array}{l}q_{\mathrm{e}} \text { experimental } \\
\left(\mathrm{mg} \mathrm{g}^{-1}\right)\end{array}$ & $\begin{array}{l}q_{\mathrm{e}} \text { calculated } \\
\left(\mathrm{mg} \mathrm{g}^{-1}\right)\end{array}$ & $k_{2}\left(\mathrm{~g} \mathrm{mg}^{-1} \mathrm{~min}^{-1}\right)$ & $R^{2}$ \\
\hline $\mathrm{Pb}(\mathrm{II})$ & 49.4 & 49.5 & 0.03781 & 1 \\
$\mathrm{Cd}(\mathrm{II})$ & 47.7 & 47.8 & 0.00513 & 0.9999 \\
$\mathrm{Cu}(\mathrm{II})$ & 47.2 & 47.5 & 0.00209 & 0.9999 \\
\hline
\end{tabular}

\subsection{Adsorption kinetics}

The adsorption mechanisms of CS-HA were studied employing pseudo-first-order and pseudo-second-order kinetic methods. Lagergren pseudo-first-order equation is written as:

$$
\ln \left(q_{\mathrm{e}}-q_{\mathrm{t}}\right)=\ln q_{\mathrm{e}}-k_{1} t
$$

Ho pseudo-second-order equation is written as:

$$
\frac{t}{q_{\mathrm{t}}}=\frac{1}{k_{2} q_{\mathrm{e}}^{2}}+\frac{1}{q_{\mathrm{e}}} t
$$

where $q_{\mathrm{e}}\left(\mathrm{mg} \mathrm{g}^{-1}\right)$ and $q_{\mathrm{t}}\left(\mathrm{mg} \mathrm{g}^{-1}\right)$ are the removal capacity of pollutants at equilibrium and at time $t(\mathrm{~min})$ respectively. $k_{1}$ $\left(\mathrm{min}^{-1}\right)$ and $k_{2}\left(\mathrm{~g} \mathrm{mg}^{-1} \mathrm{~min}^{-1}\right)$ are the velocity constant of firstorder kinetics and second-order, respectively. The Lagergren's $k_{1}$ and $q_{\mathrm{e}}$ constants are calculated from plotting $\ln \left(q_{\mathrm{e}}-q_{\mathrm{t}}\right)$ versus $t$, while $k_{2}$ and $q_{\mathrm{e}}$ are calculated from plotting $t / q_{\mathrm{t}}$ versus $t$.

The pseudo-second-order kinetics is the best fitting model (see Fig. 6; Table 1), indicating that the rate limiting step describing the adsorption process may be chemisorption rather than physical sorption..$^{40}$ The correlation factor $\left(R^{2}\right)$ for the pseudo-first order kinetics for the adsorption of $\mathrm{Pb}$ (II), $\mathrm{Cd}$ (II), and $\mathrm{Cu}$ (II) were lower than that obtained for the pseudo-second order kinetics, 0.42, 0.92, 0.96 respectively (data not shown). Differences between the theoretical capacity at the equilibrium and experimental values are marginal using pseudo-second-order kinetics.

\subsection{Adsorption isotherms}

The distribution of metal ions between liquid and solid phases can be described by Langmuir and Freundlich isotherm models. Experimental data was fitted using linear regressions to determine the best fit to these isotherms (see Fig. 6).

The Langmuir adsorption isotherm quantitatively describes the deposition of a large layer of molecules on an adsorbent surface as a function of the concentration of the adsorbed material in the liquid with which it is in contact. ${ }^{41}$ The Langmuir isotherm is described by the equation:

$$
q_{\mathrm{e}}=\frac{k_{\mathrm{L}} q_{\mathrm{m}} C_{\mathrm{e}}}{1+k_{\mathrm{L}} C_{\mathrm{e}}}
$$

The Freundlich isotherm is represented by the equation:

$$
q_{\mathrm{e}}=k_{\mathrm{F}} C_{\mathrm{e}^{\frac{1}{n}}}
$$


Table 2 Langmuir parameters for the sorption of $\mathrm{Pb}(॥), \mathrm{Cd}(॥)$, and $\mathrm{Cu}(॥)$ on CS-HA

\begin{tabular}{lllll}
\hline & $\begin{array}{l}q \text { experimental } \\
\left(\mathrm{mg} \mathrm{g}^{-1}\right)\end{array}$ & $q_{\mathrm{m}}\left(\mathrm{mg} \mathrm{g}^{-1}\right)$ & $k_{\mathrm{L}}\left(\mathrm{L} \mathrm{mg}^{-1}\right)$ & $R^{2}$ \\
\hline $\mathrm{Pb}(\mathrm{II})$ & 265 & 263.2 & 0.089 & 0.99 \\
$\mathrm{Cd}(\mathrm{II})$ & 64 & 62.5 & 0.058 & 0.97 \\
$\mathrm{Cu}(\mathrm{II})$ & 55 & 55.9 & 0.060 & 0.99
\end{tabular}

Table 3 Freundlich parameters for the sorption of $\mathrm{Pb}(॥), \mathrm{Cd}(॥)$, and $\mathrm{Cu}(\mathrm{II})$ on CS-HA

\begin{tabular}{llll}
\hline & $n$ & $K_{\mathrm{F}}\left(\mathrm{mg} \mathrm{g}^{-1}\right)\left(\mathrm{mg} \mathrm{L}^{-1}\right)^{-n}$ & $R^{2}$ \\
\hline $\mathrm{Pb}($ II) & 0.11 & $3.6 \times 10^{-19}$ & 0.95 \\
$\mathrm{Cd}($ II) & 4.01 & 15.86 & 0.96 \\
$\mathrm{Cu}$ (II) & 5.59 & 19.48 & 0.99 \\
\hline
\end{tabular}

where $q_{\mathrm{e}}$ is the amount of the adsorbate on the surface of the adsorbent at the equilibrium ( $\left.\mathrm{mg} \mathrm{g}^{-1}\right), C_{\mathrm{e}}$ is the equilibrium concentration of the adsorbate in solution $\left(\mathrm{mg} \mathrm{L}^{-1}\right), q_{\mathrm{m}}$ is the maximum adsorption capacity $\left(\mathrm{mg} \mathrm{g}^{-1}\right)$, and $k_{\mathrm{L}}$ is the Langmuir adsorption constant $\left(\mathrm{L} \mathrm{mg}^{-1}\right)$ related to the affinity of the binding sites and also indicates the binding energy of the adsorption reaction between adsorbate and adsorbent. $k_{\mathrm{F}}$ is the Freundlich adsorption constant $\left(\left(\mathrm{mg} \mathrm{g}^{-1}\right)\left(\mathrm{mg} \mathrm{L}^{-1}\right)^{-n}\right)$, which is a relative indicator of adsorption capacity and $n$ represents the intensity of the reaction and indicating the favorability and capacity of the adsorbent/adsorbate system. $k_{\mathrm{L}}$ and $q_{\mathrm{m}}$ are calculated by plotting $C_{\mathrm{e}} / q_{\mathrm{e}}$ versus $C_{\mathrm{e}}$ for the Langmuir isotherm. Thus, $k_{\mathrm{F}}$ and $n$ are calculated by plotting $\ln \left(q_{\mathrm{e}}\right)$ versus $\ln \left(C_{\mathrm{e}}\right)$ for the Freundlich isotherm.

The Langmuir model showed better fitting than the Freundlich model (see Table 2 and Table 3). The Langmuir constant accounts for better adsorption affinity of CS-HA for $\mathrm{Pb}$ (II), than that for $\mathrm{Cd}$ (II) and $\mathrm{Cu}$ (II), while affinities for $\mathrm{Cd}(\mathrm{II})$ and $\mathrm{Cu}(\mathrm{II})$ were similar. In addition, differences between the maximal theoretical adsorption capacity and the highest adsorption capacity experimentally determined are minimal.

The highest sorption capacity for $\mathrm{Cd}(\mathrm{II})$ obtained herein is similar to that reported by Smiciklas et al. ${ }^{22}$ Cheung et al. ${ }^{32}$ and $\mathrm{Xu}$ et al. $^{17}$ using chemically produced HA, bone char and commercial HA, respectively (see Table 4). However, this value is lower than the sorption capacities obtained by Dybowska et al. ${ }^{25}$ and Corami et al., ${ }^{21}$ using chemically produced HA and commercial $\mathrm{HA}$, respectively. In terms of $\mathrm{Cu}$ (II) sorption, the capacities obtained in our study are higher than those obtained by Smiciklas et al.,${ }^{22} \mathrm{Xu}$ et al.,${ }^{17}$ Corami et al. ${ }^{21}$ and Wang et al. ${ }^{26}$ but lower than sorption capacities reported by Dybowska et al. ${ }^{25}$ Finally, the $\mathrm{Pb}$ (II) maximal removal capacity experimentally determined in this study with CS-HA was 2-3 times lower than the values reported by Smiciklas et al. ${ }^{22}$ Dybowska et al. ${ }^{25}$ and Ibrahim et al. ${ }^{28}$ (see Table 4).

\subsection{Column studies}

The behavior of the adsorption column packed with CS-HA was studied for 400 min using a solution of $\mathrm{Pb}$ (II) prepared at $30 \mathrm{mg} \mathrm{L}^{-1}$ and $\mathrm{pH}$ 5. The breakthrough curve plotted in Fig. 7 shows the outflow concentration of the metal that increases constantly until around $60 \%$ of the initial concentration, after which it starts to decline at about 280 min of operation.

The adsorption capacity of the column was calculated according to the eqn (6) and (7), and the efficiency of the column was calculated using eqn (8).

$$
\begin{gathered}
q_{\text {total }}=\sum_{t=0}^{t=\text { end }} \frac{Q\left(C_{0}-C_{t}\right)\left(t_{t}-t_{t-1}\right)}{1000} \\
q_{\text {eq }}=\frac{q_{\text {total }}}{X}
\end{gathered}
$$

$$
\text { Column efficency }(\%)=\frac{q_{\text {total }}}{C_{0} Q t_{\text {total }}}
$$

where, the total amount of the adsorbed metal is expressed as $q_{\text {total }}(\mathrm{mg})$, the total amount of the adsorbed metal per amount of adsorbent material is indicated by $q_{\mathrm{eq}}\left(\mathrm{mg} \mathrm{g}^{-1}\right)$, and $C_{0}$ is the initial concentration, $Q$ is the operational flow, $C_{t}$ is the concentration at time $t$, and $X$ is the amount of the CS-HA loaded into the column ( $\mathrm{g}$ ).

The adsorption capacity reached a value of $42.5 \mathrm{mg} \mathrm{g}^{-1}$ during the total time of operation of the CS-HA packed bed column (see Table 5).This capacity is lower than the value calculated in batch experiments, since the contact time between the liquid and solid phase in the column is significantly lower (empty bed residence time $=1 \mathrm{~min}$ ) than the contact time employed in batch mode $(60 \mathrm{~min})$. The column removal

Table $4 \mathrm{Cu}(॥), \mathrm{Cd}(॥)$, and $\mathrm{Pb}(॥)$ sorption capacities obtained from different sources of $\mathrm{HA}$

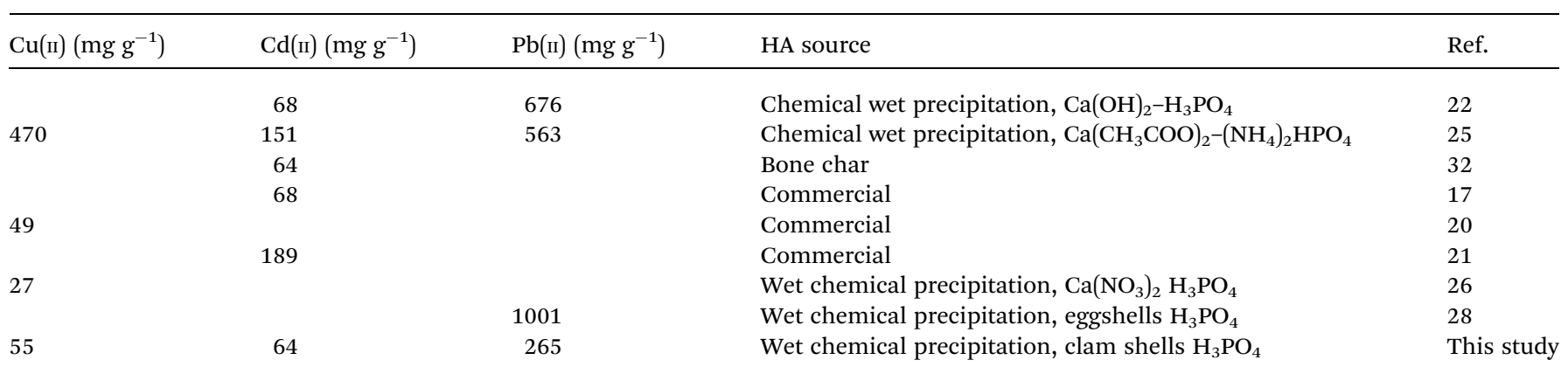




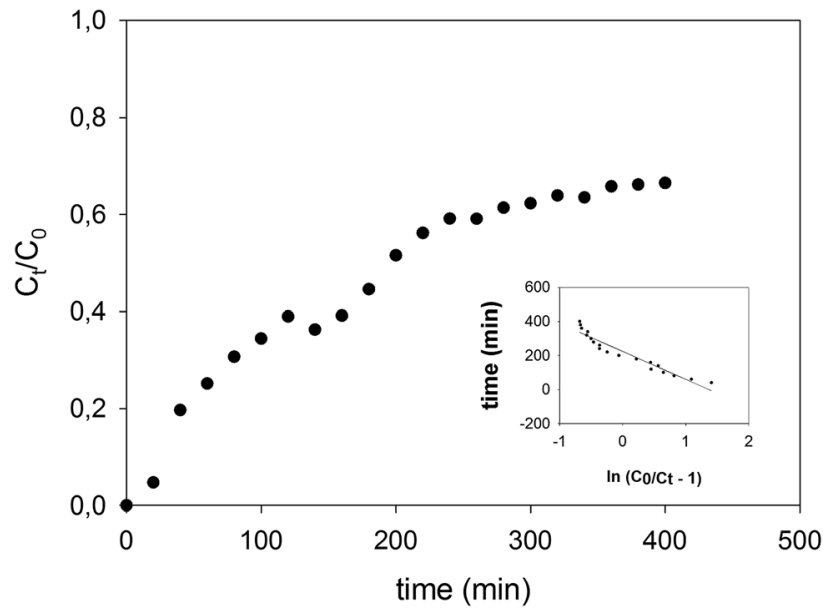

Fig. 7 Breaking through curve of the CS-HA packed bed column operated at $1.3 \mathrm{~mL} \mathrm{~min}^{-1}$, using a solution of $30 \mathrm{mg} \mathrm{L}^{-1}$ of $\mathrm{Pb}($ (I) at $\mathrm{pH} 5$. Inside graph indicates fitting to Thomas model $\left(R^{2}=0.92\right)$.

Table 5 Operational parameters of $\mathrm{Pb}(॥)$ adsorption in a column system packed with CS-HA

Total volume

fed $(\mathrm{mL}) \quad$ Adsorption capacity $\left(\mathrm{mg} \mathrm{g}^{-1}\right) \quad$ Column efficiency (\%)

$\begin{array}{lll}993 & 42.5 & 52.6\end{array}$

efficiency determined from eqn (8) was $52.6 \%$ of the total amount of metal ion fed in the solution.

Experimental data was fitted to the Thomas model, which is used to predict column performance under different operational conditions. The Thomas model equation ${ }^{42}$ is described in eqn (9).

$$
\ln \left(\frac{C_{t}}{C_{0}}-1\right)=K_{\mathrm{th}} q_{\mathrm{m}} \frac{X}{Q}-K_{\mathrm{th}} C_{i} t
$$

where $C_{t}\left(\mathrm{mg} \mathrm{L}^{-1}\right)$ is the outlet concentration at the time $t, C_{0}$ $\left(\mathrm{mg} \mathrm{L}^{-1}\right)$ is the inlet concentration, $K_{\mathrm{th}}\left(\mathrm{mL} \mathrm{h}^{-1} \mathrm{mg}^{-1}\right)$ is the Thomas adsorption constant, $q_{\mathrm{m}}\left(\mathrm{mg} \mathrm{g}^{-1}\right)$ is the maximum equilibrium capacity of the adsorbent, $X(\mathrm{~g})$ is the mass of the adsorbent packed in the column, and $Q\left(\mathrm{~mL} \min ^{-1}\right)$ is the operational flow.

The Thomas model showed good linear relation for $\mathrm{Pb}(\mathrm{II})$ for the packed bed column system $\left(R^{2}=0.92, K_{\mathrm{th}}=1.9 \times 10^{-4}\right)$. This model considers that the sorption process is controlled by the mass transfer at the interface; it allows the scaling up of the process by predicting the column behavior.

\section{Conclusion}

HA nanocrystals produced from clam shells as starting material showed excellent sorption capacities to remove $\mathrm{Pb}$ (II), $\mathrm{Cu}$ (II) and Cd(II) from aqueous solution. The experiment carried out in column equilibrium procedure showed good performance, reaching up to $42.5 \mathrm{mg} \mathrm{g}^{-1}$ of removal capacity in shorter residence time when compared with batch experiments. Additionally, Thomas model showed good fitting to the experimental data and, therefore, could be used to predict column behavior and scaling up the adsorption process.

\section{Conflicts of interest}

The authors declare no conflicts of interest.

\section{Acknowledgements}

The present research was funded by the National Commission of Scientific Research and Technology (CONICYT, Chile): PAI Grant No 7815020005, FONDECYT Grant No 1150510 and CONICYT Regional Grant No R16F10013. The authors also acknowledge the scholarship given to Aritz Mancisidor and Jon Ander Serrano by the Global Training Internationalization Program from the Basque Government (Spain); and CIPA, CONICYT Regional, GORE BIO BIO, R17A10003.

\section{References}

1 M. A. Shannon, P. W. Bohn, M. Elimelech, J. G. Georgiadis, B. J. Mariñas and A. M. Mayes, Nature, 2008, 452, 301-310.

2 P. K. Samantaray, S. Baloda, G. Madras and S. Bose, J. Mater. Chem. A, 2018, 6, 16664-16679.

3 G. Flora, D. Gupta and A. Tiwari, Interdiscip. Toxicol., 2012, 5, 47-58.

4 P. B. Tchounwou, C. G. Yedjou, A. K. Patlolla and D. J. Sutton, Exper. Suppl., 2012, 101, 133-164.

5 F. L. Fu and Q. Wang, J. Environ. Manage., 2011, 92, 407-418.

6 J. G. Dean and F. L. Bosqui, Environ. Sci. Technol., 1972, 6, 518-522.

7 D. Prabhakaran and M. S. Subramanian, Talanta, 2003, 59, 1227-1236.

8 M. M. Jadhao, L. J. Paliwal and N. S. Bhave, Desalination, 2009, 247, 456-465.

9 B. L. Rivas and I. Moreno-Villoslada, J. Appl. Polym. Sci., 1998, 69, 817-824.

10 B. L. Rivas, L. N. Schiappacasse, U. E. Pereira and I. MorenoVilloslada, Polymer, 2004, 45, 1771-1775.

11 D. Nunez, E. Elgueta, K. Varaprasad and P. Oyarzun, Mater. Lett., 2018, 230, 64-68.

12 M. Akram, R. Ahmed, I. Shakir, W. A. W. Ibrahim and R. Hussain, J. Mater. Sci., 2014, 49, 1461-1475.

13 D. Milovac, G. Gallego Ferrer, M. Ivankovic and H. Ivankovic, Mater. Sci. Eng. C Mater. Biol. Appl., 2014, 34, 437-445.

14 N. A. S. Mohd Pu'ad, P. Koshy, H. Z. Abdullah, M. I. Idris and T. C. Lee, Heliyon, 2019, 5, e01588.

15 D. Prema, S. Gnanavel, S. Anuraj and C. Gopalakrishnan, Mater. Today: Proc., 2018, 5, 8868-8874.

16 F. Ye, H. Guo, H. Zhang and X. He, Acta Biomater., 2010, 6, 2212-2218.

17 Y. P. Xu, F. W. Schwartz and S. J. Traina, Environ. Sci. Technol., 1994, 28, 1472-1480.

18 J. A. Gomez del Rio, P. J. Morando and D. S. Cicerone, J. Environ. Manage., 2004, 71, 169-177. 
19 I. Smiciklas, S. Dimovic, I. Plecas and M. Mitric, Water Res., 2006, 40, 2267-2274.

20 A. Corami, S. Mignardi and V. Ferrini, J. Hazard. Mater., 2007, 146, 164-170.

21 A. Corami, S. Mignardi and V. Ferrini, J. Colloid Interface Sci., 2008, 317, 402-408.

22 I. Smiciklas, A. Onjia, S. Raicevic, D. Janackovic and M. Mitric, J. Hazard. Mater., 2008, 152, 876-884.

23 D. Gogoi, A. G. Shanmugamani, S. V. S. Rao, T. Kumar and S. Velmurugan, Desalin. Water Treat., 2015, 57, 6566-6574.

24 V. N. Narwade, M. P. Mahabole, A. K. Bogle and R. S. Khairnar, Int. J. Innov. Sci. Mod. Eng., 2014, 3, 324-329.

25 A. Dybowska, D. A. C. Manning, M. J. Collins, T. Wess, S. Woodgate and E. Valsami-Jones, Sci. Total Environ., 2009, 407, 2953-2965.

26 Y. J. Wang, J. H. Chen, Y. X. Cui, S. Q. Wang and D. M. Zhou, J. Hazard. Mater., 2009, 162, 1135-1140.

27 S. Zamani, E. Salahi and I. Mobasherpour, Can. Chem. Trans., 2013, 1, 173-190.

28 A. R. Ibrahim, Y. L. Zhou, X. Y. Li, L. Chen, Y. Z. Hong, Y. Z. Su, H. T. Wang and J. Li, Mater. Res. Bull., 2015, 62, 132-141.

29 S. Meski, S. Ziani and H. Khireddine, J. Chem. Eng. Data, 2010, 55, 3923-3928.

30 D. X. Liao, W. Zheng, X. M. Li, Q. Yang, X. Yue, L. Guo and G. M. Zeng, J. Hazard. Mater., 2010, 177, 126-130.
31 W. Zheng, X.-m. Li, Q. Yang, G.-m. Zeng, X.-x. Shen, Y. Zhang and J.-j. Liu, J. Hazard. Mater., 2007, 147, 534-539.

32 C. W. Cheung, J. F. Porter and G. McKay, Water Res., 2001, 35, 605-612.

33 S. Kongsri, K. Janpradit, K. Buapa, S. Techawongstien and S. Chanthai, J. Chem. Eng., 2013, 215, 522-532.

34 M. Wang, S. Wu, J. Guo, X. Zhang, Y. Yang, F. Chen and R. Zhu, J. Hazard. Mater., 2018, 366, 684-693.

35 W. Wei, L. Yang, W. H. Zhong, S. Y. Li, J. CUI and Z. G. Wei, Dig. J. Nanomater. Bios., 2015, 10, 1343-1363.

36 A. Ansari, S. Vahedi, O. Tavakoli, M. Khoobi and M. A. Faramarzi, Appl. Organomet. Chem., 2019, 33, e4634.

37 Z. Chen, Y. Liu, L. Mao, L. Gong, W. Sun and L. Feng, Ceram. Int., 2018, 44, 6002-6009.

38 Periodic Table of Elements Sorted by Electronegativity (Pauling), http://EnvironmentalChemistry.com/yogi/ periodic/electronegativity.html, (accesed June 2 2018).

39 T. Suzuki, T. Hatsushika and M. Miyake, J. Chem. Soc., Faraday Trans. 1, 1982, 78, 3605-3611.

40 Y. S. Ho, J. C. Y. Ng and G. McKay, Sep. Sci. Technol., 2001, 36, 241-261.

41 K. Y. Foo and B. H. Hameed, Chem. Eng. J., 2010, 156, 2-10. 42 H. T. Van, L. H. Nguyen, V. D. Nguyen, X. H. Nguyen, T. H. Nguyen, T. V. Nguyen, S. Vigneswaran, J. Rinklebe and H. N. Tran, J. Environ. Manage., 2018, 241, 535-548. 